$\checkmark$ Research Square
Preprints are preliminary reports that have not undergone peer review.

They should not be considered conclusive, used to inform clinical practice, or referenced by the media as validated information.

\title{
Distribution of Genes Encoding Virulence Factors of Shigella Strains Isolated from Children with Diarrhea in Southwest Iran.
}

\section{maryam Afzali}

infectious tropica disease research center health research inestitue ahvaz jundishapur university of medical sciences ahvaz,Iran

nabi jomehzadeh Abadan faculty of medical sciences, Abadan, Iran.

khadijeh ahmadi ( $\sim$ kh.ahmadi53@gmail.com ) Ahvaz Jondishapour University of Medical Sciences Abadan Faculty of Nursing and Midwifery Abadan https://orcid.org/0000-0003-0012-2393

\section{Research}

Keywords: Shigella, diarrhea, virulence factor, PCR

Posted Date: May 28th, 2020

DOI: https://doi.org/10.21203/rs.3.rs-29988/v1

License: (9) This work is licensed under a Creative Commons Attribution 4.0 International License. Read Full License 


\section{Abstract}

Background: This study aimed to investigate the distribution of virulence factor genes in Shigella strains isolated from children with diarrhea in the southwest, Iran.

Methods: In this cross-sectional study, a total of 91 Shigella spp. were isolated from diarrhea specimens of 1530 children aged under 15 years in Ahvaz and Abadan, southwest Iran. The Shigella strains were identified by biochemical methods. Subsequently, Shigella spp. were identified by polymerase chain reaction (PCR).All Shigella spp evaluated by PCR for the presence of 9 virulence genes (ipaH, ial, virF, invE, sat, sigA, pic, pet, and $\operatorname{sep} A)$.

Results: A total of 91 isolates including 47 S. flexneri, 36 S. sonnei, and 8 S. boydii were identified. All isolates were positive for the ipaH gene. The other genes include ial, virF, invE, sigA, sat, sepA, pic and pet found in $84.6 \%, 72.5 \%, 68.1 \%, 62.6 \%, 51.6 \%, 39.5 \%, 37.3 \%$ and $28.5 \%$ of the isolates, respectively.

Conclusion: Our results showed a high distribution of virulence genes among Shigella strains in our region. It seems that for different Shigella spp. different virulence factors contribute to pathogenesis. The current study provided insights into some baseline information about the distribution of some virulence genes of Shigella isolates in Southwest Iran.

\section{Background}

Shigellosis is an acute gastroenteritis infection caused by Shigella species. It is one of the most common causes of morbidity and mortality, especially in children in developing countries [1]. Shigellosis is characterized by fever, abdominal cramps, mucoid stool, and bloody diarrhea [2]. The severity of Shigellosis is depended on the various virulence factors located in the chromosome or large virulent inv plasmids [3]. The invasion plasmid antigen $\mathrm{H}(\mathrm{ipaH})$ genes are present in multiple copies located on a both plasmid and the chromosome is responsible for dissemination in epithelial cells [4]. The invasionassociated locus (ial) gene, which is located on a plasmid, is involved in cell penetration by Shigella [4]. Two regulatory proteins, virF and invE are involved in control the transcriptional of invasion genes [5]. The serin autotransporters of proteins Enterobacteriaceae (SPATEs) are present in Shigella strains. The SPATEs family has been divided into two classes. Class 1 SPATEs members include the plasmid-encoded toxin gene (pet), secreted autotransporter toxin gene (sat), and Shigella IgA-like protease homolog gene $(\operatorname{sig} A)$, which are cytotoxic for epithelial cells. The protease involved in colonization of the intestine (pic) and the extracellular protein Shigella A $(\operatorname{sep} A)$ are members of class 2 , which contribute to intestinal inflammation and colonization [6]. Shigella isolates harboring virulence genes can induce extensive mucosal damages and inflammation in intestinal cells, especially when these strains encode more than one of the virulence factors.

Despite many reports about the prevalence and antimicrobial resistance of Shigella from different parts of the world and Iran, investigations about the prevalence of virulence factors in Shigella spp. are still rare 
worldwide. Therefore, we investigated the distribution of genes encoding virulence factors of Shigella strains isolated from children with diarrhea in southwest Iran.

\section{Materials And Methods Bacterial Isolates}

In this cross-sectional study, 1530 stool samples were collected from patients with diarrhea referring to the teaching hospitals in Ahvaz and Abadan, southwest of Iran, for 18 months from April 2017 to September 2018. Patients with a history of fever, abdominal cramps, vomiting, watery and bloody diarrhea were included in our study. All isolates were identified by standard biochemical tests [7]. All isolates that confirmed as Shigella spp. were stored in Tryptic Soy Broth (TSB) (Merck, Germany), containing glycerol $(30 \%)$ at $-70^{\circ} \mathrm{C}$.

\section{Molecular Confirmation of Shigella Strains}

All Shigella strains were evaluated for the presence of the ipaH gene by PCR. DNA extraction of isolates was performed by the boiling method previously described [8]. The sequences of primers and annealing temperatures of the $i p a H$ gene are shown in Table 1. PCR conditions were examined according to the protocol as described previously [6]. S. flexnery ATCC 12122 was used as a positive PCR control for the ipaHgene. 
Primers Used to Identify Virulence-Associated Genes of Shigella spp.

\begin{tabular}{|c|c|c|c|c|}
\hline $\begin{array}{l}\text { Target } \\
\text { gene }\end{array}$ & Primer sequences & $\begin{array}{l}\text { Product } \\
\text { size } \\
\text { (bp) }\end{array}$ & $\begin{array}{l}\text { Annealing } \\
\text { Temperature }\left({ }^{\circ} \mathrm{C}\right)\end{array}$ & References \\
\hline \multirow[t]{2}{*}{ ipaH } & F-GAAAACCCTCCTGGTCCATCAGG & 619 & 58 & 6 \\
\hline & R-GCCGGTCAGCCACCCTCTGAGAGTAC & & & \\
\hline \multirow[t]{2}{*}{ sat } & F-TCAGAAGCTCAGCGAATCATTG & 930 & 59 & 6 \\
\hline & R-CCATTATCACCAGTAAAACGCACC & & & \\
\hline \multirow[t]{2}{*}{ ial } & F- CTGGATGGTATGGTGAGG & 320 & 59 & 6 \\
\hline & R-GGAGGCCAACAATTATTTCC & & & \\
\hline \multirow[t]{2}{*}{ virF } & F- TCAGGCAATGAAACTTTGAC & 618 & 58 & 6 \\
\hline & R-GGGCTTGATATTCCGATAAGTC & & & \\
\hline \multirow[t]{2}{*}{ invE } & $\begin{array}{l}\text { F- } \\
\text { CGATAGATGGCGAGAAATTATATCCCG }\end{array}$ & 766 & 59 & 6 \\
\hline & $\begin{array}{l}\text { R- } \\
\text { CGATCAAGAATCCCTAACAGAAGAATCA }\end{array}$ & & & \\
\hline \multirow[t]{2}{*}{ sigA } & F- CCGACTTCTCACTTTCTCCCG & 430 & 58 & 6 \\
\hline & R- CCATCCAGCTGCATAGTGTTTG & & & \\
\hline \multirow[t]{2}{*}{ pet } & F-GGC ACA GAA TAA AGG GGT GTT & 302 & 58 & 9 \\
\hline & T; R-CCT CTT GTT TCC ACG ACA TAC & & & \\
\hline \multirow[t]{2}{*}{ pic } & F- ACTGGATCTTAAGGCTCAGGAT & 572 & 58 & 6 \\
\hline & R-GACTTAATGTCACTGTTCAGCG & & & \\
\hline \multirow[t]{2}{*}{ Sep A } & F- GCAGTGGAAATATGATGCGGC & 794 & 58 & 6 \\
\hline & R-TTGTTCAGATCGGAGAAGAACG & & & \\
\hline
\end{tabular}

\section{PCR assay for molecular identification of Shigella species}

PCR was carried out on all Shigella strains to evaluate the prevalence of the $r f c, w b g Z$, rfpB, hypothetical protein genes. PCR was performed according to a previous study [7].

The specific primers and annealing temperatures of Shigella spp. genes are listed in Table 2. S. sonnei ATCC25931, S. flexneri ATCC29903, S. boydii ATCC8700, and S. dysenteriae ATCC13313 were used as a positive control. 
Table 2

Primers used for identifying each Shigella spp.

\begin{tabular}{|c|c|c|c|c|}
\hline Target gene & Primer sequences & $\begin{array}{l}\text { Product } \\
\text { size } \\
\text { (bp) }\end{array}$ & $\begin{array}{l}\text { Annealing } \\
\text { Temperature }\left({ }^{\circ} \mathrm{C}\right)\end{array}$ & References \\
\hline \multirow[t]{2}{*}{$\begin{array}{l}\text { Hypothetical } \\
\text { protein }\end{array}$} & $\begin{array}{l}\text { F: } \\
\text { GAGCACGGAAACAGAGAGCGCC }\end{array}$ & 240 & 63 & 7 \\
\hline & $\begin{array}{l}\text { R: } \\
\text { GGTGCGTTCTTCCGGTGTTCTG }\end{array}$ & & & \\
\hline \multirow[t]{2}{*}{ wbgZ } & F: TCTGAATATGCCCTCTAC & 430 & 60 & 7 \\
\hline & R: GACAGAGCCCGAAGAACCG & & & \\
\hline \multirow[t]{2}{*}{ Rfc } & F: TTTATGGCTTCTTTGTCG & 537 & 60 & 7 \\
\hline & R: CTGCGTGATCCGACCATG & & & \\
\hline \multirow[t]{2}{*}{ rfpB } & $\begin{array}{l}\text { F: } \\
\text { TCTCAATAATAGGGAACACAGC }\end{array}$ & 211 & 59 & 7 \\
\hline & R: CATAAATCACCAGCAAGGTT & & & \\
\hline
\end{tabular}

\section{Amplification of virulence factors genes}

PCR was performed for all Shigella strains to evaluate the prevalence of the ial, virF, invE, pet, sat, sigA, $p i c$, and $\operatorname{sep} A[6,9]$. The sequences of primers and annealing temperatures are shown in Table 1 . The total volume of the PCR mixture was $25 \mu \mathrm{L}$, containing $0.5 \mu \mathrm{L}$ of DNA template, 1 X PCR buffer, $2.5 \mathrm{Mm}$ of $\mathrm{MgCl} 2,0.5 \mu \mathrm{L}$ each virulence gene primer, $0.5 \mu \mathrm{L}$ Taq DNA polymerase. The PCR conditions for the amplification of virulence genes included an initial denaturation at $94{ }^{\circ} \mathrm{C}$ for 60 seconds, 35 cycles of denaturation at $94^{\circ} \mathrm{C}$ for 60 seconds, annealing (variable) for 60 seconds, and extension at $72{ }^{\circ} \mathrm{C}$ for 60 seconds, as well as a final extension at $72{ }^{\circ} \mathrm{C}$ for $7 \mathrm{~min}$. After performing PCR, the size of each locus was easily determined on $1.5 \%$ gel agarose. Positive controls for each gene were as follows: S. flexnery ATCC 12122 for virF, EIEC strain 44825 for invE, EIEC strain 43893 for ial, S. flexneri 2a strain 2457T is for sat, sepA and sigA, EAEC strain 042 is the positive control for pet and pic.

\section{Statistical analysis}

The descriptive statistic tests were performed in SPSS version 16.00. Correlation between the occurrence of virulence factor genes and multidrug resistance was calculated using Fisher's exact test. A (P-value < $0.05)$ was considered statistically significant.

\section{Results}

\section{Bacterial isolation}


In this study, $5.9 \%(n=91)$ of 1530 stool samples were positive for Shigella spp. Of the 1530 patients, 47.1\% $(n=720)$ and $52.9 \%(n=810)$ were males and females, respectively. The patients have had various clinical symptoms, including vomiting 31.5\%) $n=482$ ), fever $60.9 \%$ ) $n=932$ ), abdominal pain $83.1 \%$ ) $n=$ 1271 ), watery diarrhea $77.9 \%) n=1$ 193), and dysentery $21.2 \%) n=324$ ).

From a total of 91 Shigella spp., $56.0 \%(n=51)$ and $44.0 \%(n=40)$ were isolated from male and female patients, respectively. No significant differences in Shigella infection were found between male and female patient $(P>0.05)$. Distribution of Shigella spp. isolated from the 91 diarrheic children according to age were: $1-5$ years, $59.3 \%$ ( $n=54) ; 6-10$ years, $24.1 \%(n=22) ; 11-15$ years, $16.5 \%(n=15)$. Bloody diarrhea, mucoid diarrhea and watery diarrhea were found in 14.3\% $(n=13), 7.7 \%(n=7), 62.6 \%(n=57)$ patients, respectively. Of these 91 positive samples, $51.6 \%(n=47), 39.6 \%(n=36)$ and $8.8 \%(n=8)$ samples were identified as S. flexneri, S. sonnei, and S. boydii respectively. Distribution of Shigella strains according to age group and species are shown in Table 3.

Table 3

Distribution of Shigella spp. by age [n (\%)].

\begin{tabular}{|lllll|}
\hline Age group, year & S. flexneri & S. sonnei & S. boydii \\
\hline $1-5$ & $26(28.6 \%)$ & $22(24.2 \%)$ & $6(6.5 \%)$ \\
\hline $6-10$ & $13(27.6 \%)$ & $7(19.4 \%)$ & $2(2.1 \%)$ \\
\hline $11-15$ & $8(17.02 \%)$ & $7(19.4 \%)$ & $0(0 \%)$ \\
\hline Total & $47(51.6 \%)$ & $36(39.6 \%)$ & $8(8.8 \%)$ \\
\hline
\end{tabular}

\section{Frequency of virulence factors genes}

All isolates were positive for the ipaHgenes. The detection of the virulence genes from 91 Shigella isolates $84.6 \%(n=77)$ of isolates were positive for ial, whereas $72.5 \%(n=66)$ and $68.1 \%(n=62)$ were positive for the virF and invEgenes. The data revealed that $\operatorname{sigA}$, sat, sepA, pic and pet genes found in $62.6 \%(n=57), 51.6 \%(n=47), 39.5 \%(n=36), 37.3 \%(n=34)$ and $28.5 \%(n=26)$ of the isolates, respectively. All Shigella isolates harbored at least one SPATE gene. All S. flexneri isolates harbored sat gene $(p<0.05)$, but all the $S$. sonnei and $S$. boydii isolates were negative for this gene. The prevalence of these genes among the Shigella spp is shown in Table 4. 


\begin{tabular}{|lllll|}
\hline virulence genes & S. flexneri & S. sonnei & S. boydii & Total \\
\hline pic & $18(38.2 \%)$ & $10(27.7 \%)$ & $6(75 \%)$ & $34(37.3 \%)$ \\
\hline sepA & $18(38.2 \%)$ & $12(33.3 \%)$ & $6(75 \%)$ & $36(39.5 \%)$ \\
\hline pet & $11(23.4 \%)$ & $15(41.6 \%)$ & $0 \%$ & $26(28.5 \%)$ \\
\hline sigA & $31(65.9 \%)$ & $19(52.7 \%)$ & $7(87.5 \%)$ & $57(62.6 \%)$ \\
\hline sat & $47(100 \%)$ & $0(0 \%)$ & $0(0 \%)$ & $47(51.6 \%)$ \\
\hline ial & $38(80.8 \%)$ & $31(86.1 \%)$ & $8(100 \%)$ & $77(84.6 \%)$ \\
\hline virF & $26(55.3 \%)$ & $29(80.05 \%)$ & $7(87.5 \%)$ & $62(68.1 \%)$ \\
\hline invE & $28(59.9 \%)$ & $31(86.1 \%)$ & $7(87.5 \%)$ & $66(72.5 \%)$ \\
\hline
\end{tabular}

Table 4

Distribution of the virulence genes according to Shigella species.

\section{Discussion}

Shigellosis is an acute invasive enteric infection. It is one of the important causes of morbidity and mortality in developing countries, especially among children younger than 5 years $[10,11]$. In the current study, a total of 91 Shigella spp. were isolated from diarrhea specimens of children aged under 15 years in Ahvaz, Abadan, southwest Iran. The most frequent age group in our study was age 1-5 years $(\mathrm{P}<$ $0.05)$, which was consistent with previous studies $[4,12]$. Children in this age group due to poor poor personal hygiene and lack of previous exposure and lower immune responses are more prone to shigellosis [10]. Shigella invades epithelial cells of the colon and kill them. The genes related to the invasion of Shigella are located on chromosome and plasmid [13]. Several virulence genes associated with Shigella pathogenesis have been identified. Identifying the virulence-associated genes in Shigella strains would be useful to better understand its pathogenicity. In this study, we investigated the prevalence of 9 virulence genes in Shigella isolates. The $i p a H$ gene used as a diagnostic marker for Shigella detection because this gene is found both on the chromosome and the plasmid. In our study, the $i p a H$ gene was positive for all the isolates, whereas the $i a /$ gene was detected in $84.6 \%$ that is consistent with studies that agree with other studies [14-16]. It seems that because of the ia/gene is only located on the plasmid, it is prone to lose or deletion. In the current study, the prevalence of the invE and virF genes was $64.8 \%$ and $69.2 \%$, respectively. These results are consistent with the previous study [16]. Since virF and $i n v E$ genes are located on the plasmid, they are susceptible to elimination.

Other genes that possess virulence activities are SPATE genes, which secreted autotransporters in gramnegative bacteria. There is little information about the distribution of SPATE genes in Shigella isolates. In the present study, the SigA gene has the highest frequency among class 1 SPATE genes, which is consistent with previous studies $[5,16]$. Our results implied that sigA may play an important role in the 
pathogenesis of Shigella. In our study, the sat gene was found in $100 \%$ of S. flexneri strains. In agreement with our finding Hosseini Nave et al. and Roy et al. showed that sat were present almost in all $S$. flexneri strains, but it was not found in any of $S$. sonnei and $S$. boydii strains $[16,17]$. This gene can cause damage to the intestinal epithelial cells and therefore plays a role in pathogenesis [9].

The pic and sepA genes were detected in $39.5 \%$ and $37.3 \%$ of isolates, respectively. Our results matched with the previous study from Kerman, Iran [16]. The sepA gene located on the virulence plasmid, and by the pic gene located on the chromosome. Due to storage or subculturing the plasmid might have been lost together with the sepA gene. These genes can lade to fluid accumulation, the successful colonization of Shigella isolates in intestinal cells [18]. In our study, S. boydii isolates had high rates of class 2 SPATE genes (sepA and pic) that is in agreement with the previous study [16].

\section{Conclusion}

In the present study, we provided some baseline information about the distribution of some virulence genes in clinical strains of Shigella spp. Southwest Iran. Our results showed a high distribution of virulence genes among Shigella strains in our region. It seems that for different Shigella spp. different virulence factors contribute to pathogenesis. It was found that the profile of these virulence genes correlated with serotype, period, and region.

\section{Declarations}

\section{Ethics Statement}

The study was approved by the Research Ethics Committee of the Abadan School of medical sciences (Ethical code: IR.ABADANUMS.REC1398.073), Abadan, Iran. Written informed consent was obtained from all the children's parents.

\section{Acknowledgments}

This work was supported by the Vice-Chancellor for Research grant (Grant No.98U-603) of Abadan University of Medical Science. The authors of this manuscript would like to acknowledge the laboratory and nursing personnel of children and infants ward in teaching hospitals in Ahvaz, Abadan and khorramshahr, who assisted to collect the clinical specimens.

\section{Authors' Contribution}

Maryam Afzali developed the original idea and the protocol, performed the experiments, Khadijeh Ahmadi was involved in data collection, wrote the preliminary draft and analyzed the data, Nabi Jomehzadeh revised the manuscript. 


\section{Disclosure}

The authors report no conflicts of interest in this work.

\section{Availability of data and materials}

All data generated or analysed during this study are included in this published article.

\section{References}

1. Yang $H$, Chen $G$, Zhu Y, et al. Surveillance of antimicrobial susceptibility patterns among Shigella species isolated in China during the 7-year period of 2005-2011. Annals of laboratory medicine. 2013;33(2):111-115.

2. Zhang J, Qian L, Wu Y, et al. Deletion of pic results in decreased virulence for a clinical isolate of Shigella flexneri 2a from China. BMC microbiology. 2013;13(1):31.

3. Shen Y, Qian H, Gong J, et al. High prevalence of antibiotic resistance and molecular characterization of integrons among Shigella isolates in Eastern China. Antimicrob Agents Chemother. 2013;57(3):1549-1551.

4. Sousa MÂB, Mendes EN, Collares GB, Péret-Filho LA, Penna FJ, Magalhães PP. Shigella in Brazilian children with acute diarrhoea: prevalence, antimicrobial resistance and virulence genes. Mem Inst Oswaldo Cruz. 2013;108(1):30-35.

5. Fan W, Qian H, Shang W, et al. Low distribution of genes encoding virulence factors in Shigella flexneri serotypes 1b clinical isolates from eastern Chinese populations. Gut Pathog. 2017;9(1):76.

6. Farajzadeh-Sheikh A, Savari M, Ahmadi K, Nave HH, Shahin M, Afzali M. Distribution of Genes Encoding Virulence Factors and the Genetic Diversity of Enteroinvasive Escherichia coli (EIEC) Isolates from Patients with Diarrhea in Ahvaz, Iran. Infect Drug Resist. 2020;13:119.

7. Jomehzadeh N, Afzali M, Ahmadi K, Salmanzadeh S, Mehr FJ. Antimicrobial resistance patterns and prevalence of integrons in Shigella species isolated from children with diarrhea in southwest Iran. 2020.

8. Ranjbar R, Memariani M. Multilocus variable-number tandem-repeat analysis for genotyping of Shigella sonnei strains isolated from pediatric patients. Gastroenterol Hepatol Bed Bench. 2015;8(3):225.

9. Boisen N, Ruiz-Perez F, Scheutz F, Krogfelt KA, Nataro JP. High prevalence of serine protease autotransporter cytotoxins among strains of enteroaggregative Escherichia coli. Am J Trop Med Hyg. 2009;80(2):294-301.

10. Casabonne C, González A, Aquili V, Balagué C. Prevalence and virulence genes of Shigella spp. isolated from patients with diarrhea in Rosario, Argentina. Jpn J Infect Dis. 2016;69(6):477-481. 
11. Muthuirulandi Sethuvel D, Devanga Ragupathi N, Anandan S, Veeraraghavan B. Update on: Shigella new serogroups/serotypes and their antimicrobial resistance. Letters in applied microbiology. 2017;64(1):8-18.

12. Jomezadeh N, Babamoradi S, Kalantar E, Javaherizadeh H. Isolation and antibiotic susceptibility of Shigella species from stool samples among hospitalized children in Abadan, Iran. Gastroenterol Hepatol Bed Bench. 2014;7(4):218-23.

13. Peng J, Yang J, Jin Q. The molecular evolutionary history of Shigella spp. and enteroinvasive Escherichia coli. Infect Genet Evol. 2009;9(1):147-152.

14. Yaghoubi S, Ranjbar R, Dallal MMS, Fard SY, Shirazi MH, Mahmoudi M. Profiling of virulenceassociated factors in Shigella species isolated from acute pediatric diarrheal samples in Tehran, Iran. Osong public health and research perspectives. 2017;8(3):220.

15. Cruz CBNd, Souza MCSd, Serra PT, et al. Virulence factors associated with pediatric shigellosis in Brazilian Amazon. Biomed Res Int. 2014;2014.

16. Nave HH, Mansouri S, Emaneini M, Moradi M. Distribution of genes encoding virulence factors and molecular analysis of Shigella spp. isolated from patients with diarrhea in Kerman, Iran. Microbial pathogenesis. 2016;92:68-71.

17. Roy S, Thanasekaran K, Dutta Roy AR, Sehgal SC. Distribution of Shigella enterotoxin genes and secreted autotransporter toxin gene among diverse species and serotypes of Shigella isolated from Andaman Islands, India. Trop Med Int Health. 2006;11(11):1694-1698.

18. Dautin N. Serine protease autotransporters of enterobacteriaceae (SPATEs): biogenesis and function. Toxins. 2010;2(6):1179-1206. 